\title{
New title: Trends in Psychiatry and Psychotherapy
}

\author{
Novo título: Trends in Psychiatry and Psychotherapy
}

Flávio Kapczinski, ${ }^{1}$ Jair Segal, ${ }^{2}$ Pedro Vieira da Silva Magalhães, ${ }^{2}$ Rodrigo Grassi-Oliveira ${ }^{2}$

If you are reading this editorial, you have probably noticed a significant change on the journal's cover: starting with the present issue, the Revista de Psiquiatria do Rio Grande do Sul has changed its name to Trends in Psychiatry and Psychotherapy.

The Revista de Psiquiatria do Rio Grande do Sul started to be published in 1979 as the official publication of Associação de Psiquiatria do Rio Grande do Sul (APRS). The aim of the journal has always been to provide a forum for investigators to share their research findings with policy- and decision-makers as well as with other investigators. Initially, the journal's audience was primarily our local scientific community. However, as the journal grew and its editorial line became consolidated, several initiatives started to be undertaken with the aim of changing our local journal into an international publication (several of these initiatives have been commented upon in previous issues). Now, we were finally ready for this big step, namely changing the journal's title, a decision that has been discussed for quite some time among editorial board members over the past few years.

In common with its predecessor, Trends in Psychiatry and Psychotherapy is a peer-reviewed, multidisciplinary journal interested in publishing research papers and authoritative reviews focusing on the interaction between experimental and clinical research in the field of psychiatry and mental health. The journal accepts articles whose primary focus is to help translate fundamental discoveries from basic research into the reality of clinical mental health practice, including papers on psychological processes and behavior, neuropsychology, psychopharmacology, clinical neuroscience, psychotherapy, and other areas of relevance to one or more aspects of psychopathology and psychiatry. In sum, Trends in Psychiatry and Psychotherapy aims to publish current and original research covering the broad spectrum of clinical mental health and basic science, produced by expert national and international bodies.

The journal's scope and structure will be maintained. However, from a different standpoint, the title change does reflect the commitment of the editorial board to making the journal known and respected internationally, i.e., increase its visibility. In addition, the change in title also reflects a growing preference of the journal for manuscripts written in English, as manifested in our Instructions to Authors. Although the present issue still features all articles in Portuguese, we are already observing a gradual increase in the number of Englishlanguage submissions, so the publication of future issues

${ }^{1}$ Editor-in-chief and ${ }^{2}$ associate editors, Trends in Psychiatry and Psychotherapy.

No conflicts of interest declared concerning the publication of this editorial.

Suggested citation: Kapczinski F, Segal J, Magalhães PVS, Grassi-Oliveira R. New title: Trends in Psychiatry and Psychotherapy. Trends Psychiatry Psychother. $2011 ; 33(3): 133-4$. 
with more and more articles is English is just a matter of time - as is, we would like to believe, the inclusion of the journal in international databases. Needless to say, only manuscripts written in clear and understandable language will be sent to peer review.

The current board of editors and editorial staff are all optimistic and excited about the change, and we invite authors and readers to join us and keep contributing to our journal. We are definitely not leaving 32 years of Revista de Psiquiatria do Rio Grande do Sul behind. Rather, we see this change as a natural evolution and a recognition of the great efforts made by several boards that came before us and in one way or another contributed to consolidate the journal. The change is not only desirable, but also necessary, as we feel our journal is now ready to contribute to the international body of knowledge produced in the field of psychiatry and psychotherapy. 